\title{
Clinical Relationship between Steatocholecystitis and Gallbladder Contractility Measured by Cholescintigraphy
}

\author{
Chang Seok Bang, ${ }^{1}$ Yong Sub Lee, ${ }^{1}$ Jai Hoon Yoon, ${ }^{1}$ Youn Jeong Kim, \\ Jin Bong Kim, ${ }^{1}$ and Dong Joon Kim ${ }^{1}$ \\ ${ }^{1}$ Department of Internal Medicine, Hallym University College of Medicine, 153 Gyo-dong, Chuncheon 200703, Republic of Korea \\ ${ }^{2}$ Department of Internal Medicine, The Catholic University of Korea College of Medicine, Seoul, Republic of Korea
}

Correspondence should be addressed to Jai Hoon Yoon; yoonjh@hallym.or.kr

Received 16 November 2014; Accepted 14 January 2015

Academic Editor: Spiros D. Ladas

Copyright (C) 2015 Chang Seok Bang et al. This is an open access article distributed under the Creative Commons Attribution License, which permits unrestricted use, distribution, and reproduction in any medium, provided the original work is properly cited.

\begin{abstract}
Objective. Contractility of gallbladder is known to be decreased in fatty gallbladder diseases. However, clinical estimation data about this relationship is still lacking. The aim of this study was to investigate the association between steatocholecystitis and contractility of gallbladder. Methods. Patients with cholecystitis (steatocholecystitis versus nonsteatocholecystitis) who underwent cholescintigraphy before cholecystectomy were retrospectively evaluated in a single teaching hospital of Korea. The association of steatocholecystitis with contractility of gallbladder, measured by preoperative cholescintigraphy, was assessed by univariable and multivariable analysis. Results. A total of 432 patients were finally enrolled (steatocholecystitis versus nonsteatocholecystitis; 75 versus 357 , calculous versus acalculous cholecystitis; 316 versus 116$)$. In the multivariable analysis, age (OR: 0.94, 95\% CI: 0.90-0.99, $P=0.01$ ) and total serum cholesterol (OR: 1.02, 95\% CI: 1.01-1.04, $P=0.04$ ) were related to steatocholecystitis in patients with acalculous cholecystitis. Only age (OR: $0.97,95 \%$ CI: $0.94-0.99, P=0.004)$ was significantly related to steatocholecystitis in patients with calculous cholecystitis. However, ejection fraction of gallbladder reflecting contractility measured by cholescintigraphy was not related to steatocholecystitis irrespective of presence of gallbladder stone in patients with cholecystitis. Conclusion. Ejection fraction of gallbladder measured by cholescintigraphy cannot be used for the detection or confirmation of steatocholecystitis.
\end{abstract}

\section{Introduction}

With the increasing prevalence of obesity, fatty infiltrative disease in the internal organs has been noted $[1,2]$. Fatty gallbladder disease includes cholesterol polyp or cholesterolosis results from abnormal fatty deposition in the gallbladder mucosa $[3,4]$. Pathogenic links among insulin resistance, hyperinsulinemia, and fatty gallbladder disease have been evaluated. Patients with obesity have increased cholesterol saturation in bile, which is induced by increased cholesterol synthesis and secretion of bile cholesterol $[5,6]$. Longstanding fatty deposition induces steatocholecystitis through chronic inflammation and tissue damage [7]. Recently, this type of cholecystitis is increasing and taking a substantial portion of cholecystectomy, even without definite gallbladder stone $[7,8]$.
Contractility of gallbladder is known to be decreased in fatty gallbladder disease $[7,9]$. This is induced by abnormal wall structure and decreased response of gallbladder to the neurotransmitter associated with oxidative stress and insulin resistance [10-12]. However, clinical estimation data about the relationship between steatocholecystitis and contractility of gallbladder is still lacking. The aim of this study was to investigate the relationship between steatocholecystitis and contractility of gallbladder, using preoperative cholescintigraphy.

\section{Materials and Methods}

2.1. Ethics Statement. This study was conducted in accordance with the Declaration of Helsinki and approved by an institutional review board of Chuncheon Sacred Heart 
hospital before initiating the study (2013-85). Patient records or information was anonymized and deidentified prior to analysis.

2.2. Patients and Methods. From January 2007 through July 2013, a total of 454 patients who had undergone preoperative cholescintigraphy because of cholecystitis were retrospectively evaluated in a single teaching hospital of Korea. Steatocholecystitis was determined as the state of cholecystitis combined with cholesterolosis or cholesterol polyp in gallbladder according to the final pathology report. Patients with adenomyoma, adenomyomatosis, adenoma, dysplasia, or cancer of the gallbladder, which could potentially influence the contractility of gallbladder, were all excluded. The association of steatocholecystitis with contractility of gallbladder measured by cholescintigraphy was assessed by univariable and multivariable analysis.

2.3. Cholescintigraphy. All the enrolled patients underwent cholescintigraphy before cholecystectomy for the assessment of biliary pain or cholecystitis. Patients were fasted for at least 8 hours not longer than 12 hours before administration of technetium labeled agent. The $99 \mathrm{~m}$-technetium trimethylbromo-iminodiacetic acid (mebrofenin; Amersham-GE, London, UK) was used. Sequential 5, 10, 20, 30, 45, and 60 minutes anterior images of the abdomen were obtained after the intravenous administration of $100 \mathrm{mCi}$ radiopharmaceutical agent. Then, the patients ingested standard high fat diet consisting of eggs and sandwiches and sequential anterior images of the abdomen were obtained after 80, 100, and 120 minutes. If the gallbladder was not visualized within 120 minutes, delayed images for up to $240 \mathrm{~min}$ were obtained. The interpretation of the cholescintigraphy was based on the presence or absence of biliary excretion (visualization of tracer activity in the gallbladder). If no radioactivity was detected in the gallbladder area at 4 hours after the infusion, the patient was classified as having nonvisualization of the gallbladder and the scintigraphic recording was stopped. For the calculation of gallbladder ejection fraction (GBEF), standard nuclear medicine software was used based on the following equation: GBEF $(\%)=$ (net gallbladder ${ }_{\max }$ ) - (net gallbladder $\left.{ }_{\min }\right) \times 100 /$ net gallbladder ${ }_{\max }$ [13]. The nonvisualization of gallbladder after 4 hours on scintigraphy was defined as zero \% of GBEF.

2.4. Histopathology. All resected gallbladders of enrolled patients were pathologically examined. Resected gallbladders were immediately placed in a $10 \%$ neutral buffered formalin, routinely processed and embedded in paraffin en bloc. Two sections were stained with hematoxylin and eosin. All histopathologic examinations were done by clinical pathologists and the final pathologic diagnosis was established based on consensus of two expert pathologists.

2.5. Statistical Analysis. Student $t$-test was used for the assessment of continuous variables and data were expressed as mean \pm standard deviation (SD). Fisher's exact test was used to assess the categorical variables and data were expressed as number and percentage $(n, \%)$. A multivariable logistic
TABLE 1: Clinical characteristics of total enrolled patients.

\begin{tabular}{|c|c|}
\hline Variable & $\begin{array}{c}\text { Acute cholecystitis } \\
(n=432)\end{array}$ \\
\hline Age (years, mean $\pm \mathrm{SD}$ ) & $54.4 \pm 15.7$ \\
\hline Men/women (\%) & $\begin{array}{c}202(46.8) / 230 \\
(53.2 \%)\end{array}$ \\
\hline $\mathrm{DM}(\%)$ & $48(11.1)$ \\
\hline $\operatorname{HTN}(\%)$ & $135(31.3)$ \\
\hline GB stone $(\%)$ & $316(73.1)$ \\
\hline $\mathrm{BMI}\left(\mathrm{kg} / \mathrm{m}^{2}\right.$, mean $\left.\pm \mathrm{SD}\right)$ & $24.9 \pm 3.6$ \\
\hline $\mathrm{Hb}(\mathrm{g} / \mathrm{dL}$, mean $\pm \mathrm{SD})$ & $13.6 \pm 1.8$ \\
\hline Platelet $\left(10^{3} / \mathrm{mm}^{3}\right.$, mean $\left.\pm \mathrm{SD}\right)$ & $263.3 \pm 78.9$ \\
\hline AST $(\mathrm{IU} / \mathrm{L}$, mean $\pm \mathrm{SD})$ & $30.3 \pm 24.9$ \\
\hline ALT (IU/L, mean \pm SD) & $35.1 \pm 36.5$ \\
\hline Total bilirubin $(\mathrm{mg} / \mathrm{dL}$, mean $\pm \mathrm{SD})$ & $1.0 \pm 3.1$ \\
\hline Total cholesterol $(\mathrm{mg} / \mathrm{dL}$, mean $\pm \mathrm{SD})$ & $168.2 \pm 39.3$ \\
\hline $\mathrm{TG}(\mathrm{mg} / \mathrm{dL}$, mean $\pm \mathrm{SD})$ & $110.4 \pm 73$ \\
\hline $\mathrm{LDL}(\mathrm{mg} / \mathrm{dL}$, mean $\pm \mathrm{SD})$ & $98.7 \pm 31.3$ \\
\hline $\mathrm{HDL}(\mathrm{mg} / \mathrm{dL}$, mean $\pm \mathrm{SD})$ & $50.9 \pm 14.5$ \\
\hline $\operatorname{GBEF}(\%$, mean $\pm \mathrm{SD})$ & $41.2 \pm 41.7$ \\
\hline
\end{tabular}

SD: standard deviation; $n$ : number; DM: diabetes mellitus; HTN: hypertension; GB: gallbladder; BMI: body mass index; Hb: hemoglobin; AST: aspartate aminotransferase; ALT: alanine aminotransferase; TG: triglyceride; LDL: low-density lipoprotein; HDL: high-density lipoprotein; GBEF: gallbladder ejection fraction.

regression test was used to detect the independent risk factors related to steatocholecystitis. A $P$ value $<0.05$ was considered significant for all tests. All the analyses were performed using the SPSS software, version 21.0 (IBM Corp., Armonk, NY, USA).

\section{Results}

3.1. Clinical Characteristics. During the 6-year study period, 454 patients who underwent preoperative cholescintigraphy and cholecystectomy were identified. The distribution of excluded cases is as follows: adenomyomatosis $(n=11)$, adenomyoma $(n=6)$, adenoma $(n=2)$, dysplasia $(n=2)$, and gallbladder cancer $(n=1)$ (Figure 1). After exclusion, 432 eligible patients for analysis were finally enrolled. The clinical characteristics of these patients are demonstrated in Table 1 and 2 . The mean age of the patients was $54.4 \pm 15.7$ (mean \pm SD). Two hundred two (46.8\%) men and 230 (53.2\%) women were enrolled. The proportion of the patients who had gallbladder stone was $73.1 \%(n=316)$. The mean body mass index (BMI) of the patients was $24.9 \pm 3.6$ (mean \pm SD). The characteristics of serum lipid profile were $168.2 \pm$ 39.3 in total cholesterol, $110.4 \pm 73$ in triglyceride (TG), 98.7 \pm 31.3 in low-density lipoprotein (LDL), and $50.9 \pm 14.5$ in high-density lipoprotein (HDL), respectively (mg/dL, mean \pm $\mathrm{SD})$. The mean GBEF estimated by cholescintigraphy was 41.2 \pm 41.7 (\%, mean $\pm \mathrm{SD})$. The most important variable which could influence the GBEF measured by cholescintigraphy in patients with cholecystitis is gallbladder stone. Thus, authors 


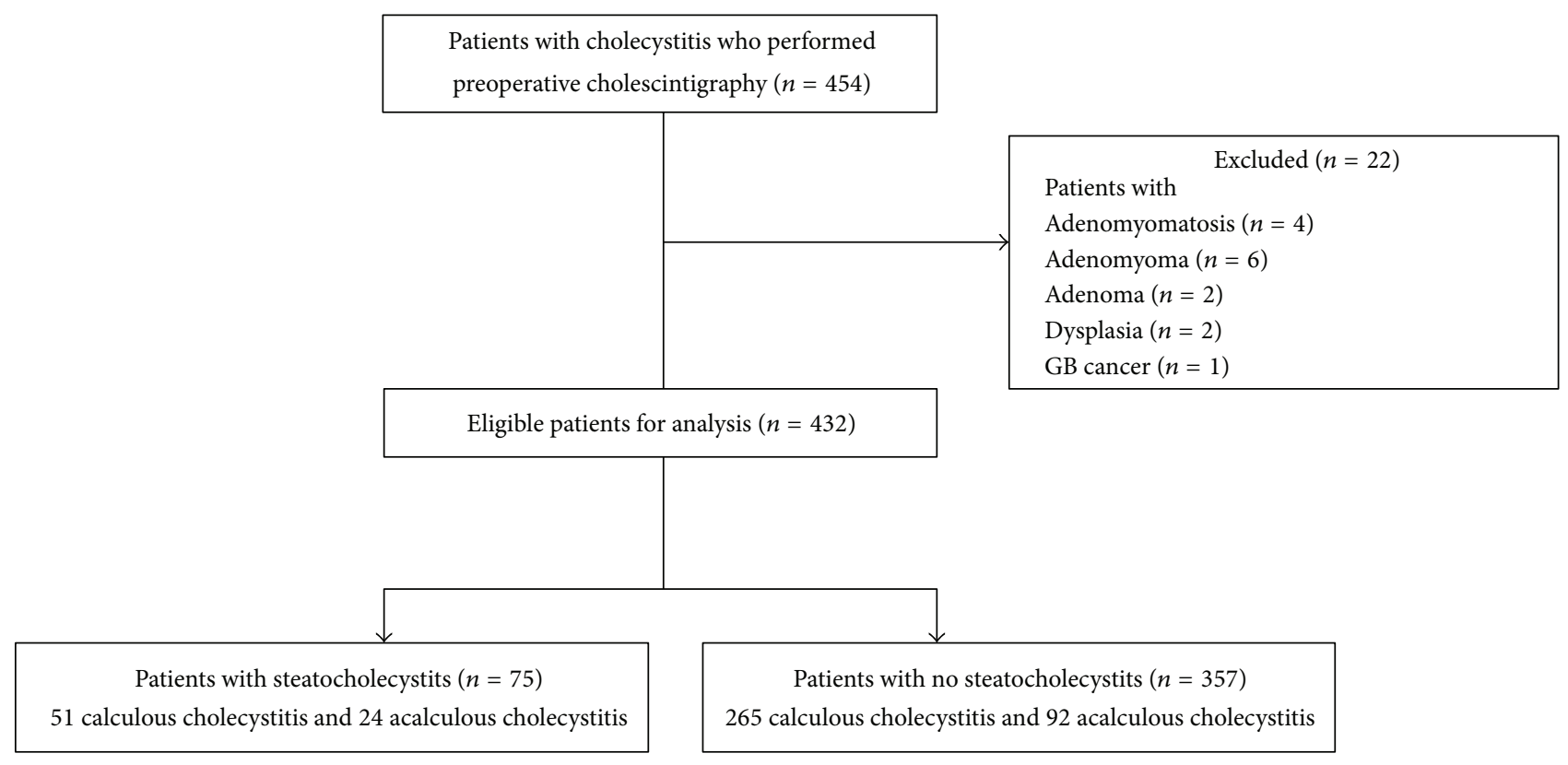

FIGURE 1: Flow chart of study design.

TABLE 2: Clinical characteristics of patients with cholecystitis.

\begin{tabular}{|c|c|c|c|}
\hline Variable & Acalculous cholecystitis $(n=116)$ & Calculous cholecystitis $(n=316)$ & $P$ value \\
\hline Age (years, mean $\pm \mathrm{SD}$ ) & $55.7 \pm 15.1$ & $53.9 \pm 16$ & 0.31 \\
\hline Men/women (\%) & $56(48.3) / 60(51.7 \%)$ & $146(46.2) / 170(53.8)$ & 0.75 \\
\hline $\mathrm{DM}(\%)$ & $11(9.5)$ & $37(11.7)$ & 0.61 \\
\hline $\operatorname{HTN}(\%)$ & $36(31)$ & $99(31.3)$ & $>0.99$ \\
\hline $\mathrm{BMI}\left(\mathrm{kg} / \mathrm{m}^{2}\right.$, mean $\left.\pm \mathrm{SD}\right)$ & $24.6 \pm 3.4$ & $25 \pm 3.7$ & 0.25 \\
\hline $\mathrm{Hb}(\mathrm{g} / \mathrm{dL}$, mean $\pm \mathrm{SD})$ & $13.6 \pm 1.7$ & $13.6 \pm 1.9$ & 0.99 \\
\hline Platelet $\left(10^{3} / \mathrm{mm}^{3}\right.$, mean $\left.\pm \mathrm{SD}\right)$ & $271.1 \pm 81.1$ & $260.4 \pm 78$ & 0.21 \\
\hline AST $(\mathrm{IU} / \mathrm{L}$, mean $\pm \mathrm{SD})$ & $30.9 \pm 18.1$ & $30.1 \pm 27$ & 0.78 \\
\hline $\operatorname{ALT}(\mathrm{IU} / \mathrm{L}$, mean $\pm \mathrm{SD})$ & $34.1 \pm 27.6$ & $35.4 \pm 39.3$ & 0.74 \\
\hline Total bilirubin $(\mathrm{mg} / \mathrm{dL}$, mean $\pm \mathrm{SD})$ & $0.9 \pm 0.8$ & $1.1 \pm 3.6$ & 0.60 \\
\hline Total cholesterol $(\mathrm{mg} / \mathrm{dL}$, mean $\pm \mathrm{SD})$ & $169.2 \pm 40.2$ & $167.9 \pm 38.9$ & 0.76 \\
\hline $\mathrm{TG}(\mathrm{mg} / \mathrm{dL}$, mean $\pm \mathrm{SD})$ & $109.6 \pm 80.6$ & $110.9 \pm 70.1$ & 0.88 \\
\hline $\mathrm{LDL}(\mathrm{mg} / \mathrm{dL}$, mean $\pm \mathrm{SD})$ & $98.3 \pm 30.5$ & $98.8 \pm 31.7$ & 0.90 \\
\hline $\mathrm{HDL}(\mathrm{mg} / \mathrm{dL}$, mean $\pm \mathrm{SD})$ & $50.6 \pm 12.6$ & $51 \pm 15.1$ & 0.84 \\
\hline $\operatorname{GBEF}(\%$, mean $\pm \mathrm{SD})$ & $38.4 \pm 40.8$ & $42.3 \pm 42$ & 0.39 \\
\hline
\end{tabular}

SD: standard deviation; $n$ : number; DM: diabetes mellitus; HTN: hypertension; GB: gallbladder; BMI: body mass index; Hb: hemoglobin; AST: aspartate aminotransferase; ALT: alanine aminotransferase; TG: triglyceride; LDL: low-density lipoprotein; HDL: high-density lipoprotein; GBEF: gallbladder ejection fraction.

performed separate analyses by patients with acalculous or calculous cholecystitis. There was no statistically significant difference in the entire estimated baseline characteristic between patients with acalculous and calculous cholecystitis (Table 2).

3.2. Univariable Analysis of Risk Factors for Steatocholecystitis. The incidence of steatocholecystitis was $17.4 \%(n=75)$ in the total population, $20.7 \%(n=24)$ in patients with acalculous cholecystitis, and $16.1 \%(n=51)$ in patients with calculous cholecystitis (Tables 3 and 5). In the univariable analysis for the risk factors for steatocholecystitis (versus nonsteatocholecystitis), age, sex, BMI, aspartate aminotransferase (AST), total bilirubin, total cholesterol, LDL, and GBEF were statistically different variables in patients with acalculous cholecystitis (Table 3). Meanwhile, age, sex, hypertension (HTN), BMI, and GBEF were statistically significant variables in patients with calculous cholecystitis for the development of 
TABLE 3: Univariable analysis for clinical risk factors of steatocholecystitis in patients with acalculous cholecystitis.

\begin{tabular}{|c|c|c|c|}
\hline Variable & $\begin{array}{c}\text { Steatocholecystitis } \\
(n=24,20.7 \%)\end{array}$ & $\begin{array}{c}\text { Nonsteatocholecystitis } \\
\quad(n=92,79.3 \%)\end{array}$ & $P$ value \\
\hline Age (years, mean $\pm \mathrm{SD}$ ) & $46.8 \pm 10.8$ & $58 \pm 15.2$ & $<0.001$ \\
\hline Men/women (\%) & $7(29.2) / 17(70.8)$ & $49(53.3) / 43(46.7)$ & 0.04 \\
\hline $\mathrm{DM}(\%)$ & $1(4.2)$ & $10(10.9)$ & 0.46 \\
\hline $\operatorname{HTN}(\%)$ & $7(29.2)$ & $29(31.5)$ & $>0.99$ \\
\hline $\mathrm{BMI}\left(\mathrm{kg} / \mathrm{m}^{2}\right.$, mean $\left.\pm \mathrm{SD}\right)$ & $26.0 \pm 3.8$ & $24.2 \pm 3.2$ & 0.02 \\
\hline $\mathrm{Hb}(\mathrm{g} / \mathrm{dL}$, mean $\pm \mathrm{SD})$ & $13.5 \pm 1.2$ & $13.6 \pm 1.8$ & 0.76 \\
\hline Platelet $\left(10^{3} / \mathrm{mm}^{3}\right.$, mean $\left.\pm \mathrm{SD}\right)$ & $284.7 \pm 69.1$ & $267.6 \pm 83.9$ & 0.36 \\
\hline AST $(I U / L$, mean \pm SD) & $25.6 \pm 10.3$ & $32.3 \pm 19.5$ & 0.03 \\
\hline $\mathrm{ALT}(\mathrm{IU} / \mathrm{L}$, mean $\pm \mathrm{SD})$ & $31.8 \pm 28.6$ & $34.7 \pm 27.4$ & 0.65 \\
\hline Total bilirubin $(\mathrm{mg} / \mathrm{dL}$, mean $\pm \mathrm{SD})$ & $0.7 \pm 0.3$ & $1.0 \pm 0.9$ & 0.01 \\
\hline Total cholesterol $(\mathrm{mg} / \mathrm{dL}$, mean $\pm \mathrm{SD})$ & $188.3 \pm 37.7$ & $164.4 \pm 39.6$ & 0.01 \\
\hline $\begin{array}{l}\mathrm{TG}(\mathrm{mg} / \mathrm{dL}, \text { mean } \pm \mathrm{SD}) \\
(\text { median/IQR })\end{array}$ & $\begin{array}{l}102.1 \pm 65 \\
76 / 69-120\end{array}$ & $\begin{array}{c}111.4 \pm 84.4 \\
91.5 / 59.5-126.8\end{array}$ & $\begin{array}{l}0.66 \\
0.65\end{array}$ \\
\hline $\mathrm{LDL}(\mathrm{mg} / \mathrm{dL}$, mean $\pm \mathrm{SD})$ & $113.1 \pm 25.1$ & $94.6 \pm 30.8$ & 0.02 \\
\hline $\mathrm{HDL}(\mathrm{mg} / \mathrm{dL}$, mean $\pm \mathrm{SD})$ & $51.7 \pm 10$ & $50.3 \pm 13.2$ & 0.67 \\
\hline $\operatorname{GBEF}(\%$, mean $\pm \mathrm{SD})$ & $61 \pm 38.1$ & $32.5 \pm 39.6$ & 0.002 \\
\hline
\end{tabular}

SD: standard deviation; $n$ : number; DM: diabetes mellitus; HTN: hypertension; GB: gallbladder; BMI: body mass index; Hb: hemoglobin; AST: aspartate aminotransferase; ALT: alanine aminotransferase; TG: triglyceride; IQR: interquartile range; LDL: low-density lipoprotein; HDL: high-density lipoprotein; GBEF: gallbladder ejection fraction.

TABLE 4: Multivariable analysis for clinical risk factors of steatocholecystitis in patients with acalculous cholecystitis.

\begin{tabular}{lcc}
\hline Variables for steatocholecystitis & OR $(95 \%$ CI $)$ & $P$ value \\
\hline Age & $0.94(0.90-0.99)$ & 0.01 \\
Sex & NS & NS \\
BMI & $1.19(0.99-1.42)$ & 0.06 \\
AST & NS & NS \\
Total bilirubin & NS & NS \\
Total cholesterol & $1.02(1.01-1.04)$ & 0.04 \\
LDL & NS & NS \\
GBEF & $1.03(0.99-1.03)$ & 0.08 \\
\hline
\end{tabular}

OR: odds ratio; CI: confidence interval; NS: not significant; BMI: body mass index; AST: aspartate aminotransferase; LDL: low-density lipoprotein; GBEF: gallbladder ejection fraction.

steatocholecystitis (versus nonsteatocholecystitis) (Table 5). Age, sex, BMI, and GBEF were the commonly detected statistically significant variables. Patients with steatocholecystitis were younger, mostly women, with higher BMI and GBEF performance.

3.3. Multivariable Analysis of Risk Factors for Steatocholecystitis. In the multivariate analysis for clinical risk factors of steatocholecystitis, age (OR: 0.94, 95\% CI: 0.90-0.99, $P=0.01)$ and total serum cholesterol (OR: $1.02,95 \% \mathrm{CI}$ : $1.01-1.04, P=0.04$ ) were associated with development of steatocholecystitis in patients with acalculous cholecystitis (Table 4). Meanwhile, only age (OR: 0.97, 95\% CI: 0.94-0.99,
$P=0.004)$ was significantly related to steatocholecystitis in patients with calculous cholecystitis (Table 6). GBEF reflecting contractility was not related to steatocholecystitis irrespective of presence of gallbladder stone in patients with cholecystitis.

\section{Discussion}

Cholesterolosis and cholesterol polyps are incidental findings detected in the cholecystectomy specimen or ultrasonic examination. Recently, however, the patients with fatty gallbladder disease are increasing and steatocholecystitis is taking a substantial portion of cholecystectomy, even without definite gallbladder stone $[7,8]$. Diagnosis is usually made by ultrasound. However, there are no specific findings indicating diffuse cholesterolosis and subjective diagnosis is usually made.

In the present study, the authors evaluated the relationship between steatocholecystitis and contractility of gallbladder, using preoperative cholescintigraphy. Another outcome was to assess the feasibility of cholescintigraphy in the detection or confirmation of steatocholecystitis. Previous studies indicated that contractility of gallbladder is decreased in patients with fatty gallbladder diseases [14-17]. The mechanism was postulated as an abnormal fatty deposition in the gallbladder mucosa associated with chronic inflammation and tissue damage, which could result in deterioration of gallbladder function $[3,4,7]$. Other multiple pathogenic links that have been reported are insulin resistance, hyperglycemia, leptin hormonal dysfunction, autonomic neuropathy, and 
TABLE 5: Univariable analysis for clinical risk factors of steatocholecystitis in patients with calculous cholecystitis.

\begin{tabular}{|c|c|c|c|}
\hline Variable & $\begin{array}{l}\text { Steatocholecystitis } \\
\quad(n=51,16.1 \%)\end{array}$ & $\begin{array}{c}\text { Nonsteatocholecystitis } \\
\quad(n=265,83.9 \%)\end{array}$ & $P$ value \\
\hline Age (years, mean $\pm \mathrm{SD}$ ) & $46.2 \pm 12.6$ & $55.4 \pm 16.1$ & $<0.001$ \\
\hline Men/women (\%) & $13(25.5) / 38(74.5)$ & $133(50.2) / 132(49.8)$ & 0.001 \\
\hline $\mathrm{DM}(\%)$ & $5(9.8)$ & $32(12.1)$ & 0.81 \\
\hline $\operatorname{HTN}(\%)$ & $9(17.6)$ & $90(34)$ & 0.02 \\
\hline $\mathrm{BMI}\left(\mathrm{kg} / \mathrm{m}^{2}\right.$, mean $\left.\pm \mathrm{SD}\right)$ & $25.9 \pm 4.1$ & $24.9 \pm 3.6$ & 0.05 \\
\hline $\mathrm{Hb}(\mathrm{g} / \mathrm{dL}$, mean $\pm \mathrm{SD})$ & $13.3 \pm 1.6$ & $13.6 \pm 1.9$ & 0.24 \\
\hline Platelet $\left(10^{3} / \mathrm{mm}^{3}\right.$, mean $\left.\pm \mathrm{SD}\right)$ & $275.8 \pm 84.3$ & $257.5 \pm 76.6$ & 0.13 \\
\hline AST $(\mathrm{IU} / \mathrm{L}$, mean $\pm \mathrm{SD})$ & $25.8 \pm 12.5$ & $31 \pm 28.9$ & 0.21 \\
\hline $\operatorname{ALT}(\mathrm{IU} / \mathrm{L}$, mean $\pm \mathrm{SD})$ & $40.4 \pm 34.4$ & $34.5 \pm 40.2$ & 0.32 \\
\hline Total bilirubin $(\mathrm{mg} / \mathrm{dL}$, mean $\pm \mathrm{SD})$ & $0.7 \pm 0.4$ & $1.2 \pm 3.9$ & 0.42 \\
\hline Total cholesterol $(\mathrm{mg} / \mathrm{dL}$, mean $\pm \mathrm{SD})$ & $169.9 \pm 35$ & $167.5 \pm 39.7$ & 0.69 \\
\hline $\begin{array}{l}\mathrm{TG}(\mathrm{mg} / \mathrm{dL}, \text { mean } \pm \mathrm{SD}) \\
(\text { median/IQR })\end{array}$ & $\begin{array}{l}102.5 \pm 69.7 \\
88 / 56.5-125\end{array}$ & $\begin{array}{c}112.3 \pm 70.2 \\
95.5 / 64.8-139\end{array}$ & $\begin{array}{l}0.43 \\
0.34\end{array}$ \\
\hline $\mathrm{LDL}(\mathrm{mg} / \mathrm{dL}$, mean $\pm \mathrm{SD})$ & $102.7 \pm 26.9$ & $98.2 \pm 32.5$ & 0.43 \\
\hline $\mathrm{HDL}(\mathrm{mg} / \mathrm{dL}$, mean $\pm \mathrm{SD})$ & $51.4 \pm 16.4$ & $50.9 \pm 14.9$ & 0.84 \\
\hline $\operatorname{GBEF}(\%$, mean $\pm \mathrm{SD})$ & $57.6 \pm 39.7$ & $39.3 \pm 41.9$ & 0.004 \\
\hline
\end{tabular}

SD: standard deviation; $n$ : number; DM: diabetes mellitus; HTN: hypertension; GB: gallbladder; BMI: body mass index; Hb: hemoglobin; AST: aspartate aminotransferase; ALT: alanine aminotransferase; TG: triglyceride; IQR: interquartile range; LDL: low-density lipoprotein; HDL: high-density lipoprotein; GBEF: gallbladder ejection fraction.

TABLE 6: Multivariable analysis for clinical risk factors of steatocholecystitis in patients with calculous cholecystitis.

\begin{tabular}{lcc}
\hline Variables for steatocholecystitis & OR $(95 \%$ CI $)$ & $P$ value \\
\hline Age & $0.97(0.94-0.99)$ & 0.004 \\
Sex & NS & NS \\
HTN & NS & NS \\
BMI & $1.10(0.99-1.22)$ & 0.06 \\
Total cholesterol & NS & NS \\
LDL & NS & NS \\
GBEF & $1.01(0.99-1.02)$ & 0.07 \\
\hline
\end{tabular}

OR: odds ratio; CI: confidence interval; NS: not significant; BMI: body mass index; AST: aspartate aminotransferase; LDL: low-density lipoprotein; GBEF: gallbladder ejection fraction.

oxidative stress [10-12]. However, clinical data which estimated the relationship between steatocholecystitis and contractility of gallbladder is lacking.

Based on the results of our study, the contractility of gallbladder measured by cholescintigraphy was not associated with steatocholecystitis. This result was consistent, irrespective of presence of gallbladder stone. The discrepancy between the results of previous studies and the present data may be explained by pitfalls of cholescintigraphy. Cholescintigraphy has the highest diagnostic accuracy of all imaging modalities for the detection of acute cholecystitis [18]. However, there are several pitfalls in this examination. False-positivity in some conditions, including insufficient or prolonged fasting state, severe hepatocellular disease, bile duct obstruction, or severe chronic cholecystitis, could lead to the inaccurate diagnosis [13]. The most important drawback is that nonvisualized gallbladder is estimated at zero \% of GBEF. In patients with acute cholecystitis, cystic duct stone or gallbladder edema even without obstructing stone could result in nonvisualized gallbladder in cholescintigraphy. This means an estimation of gallbladder contractility could be zero $\%$, even in the situation of preserved contractile function. In contrast, incomplete cystic duct obstruction or mild gallbladder wall edema could lead to false negative result in the diagnosis of acute cholecystitis. Another limitation of cholescintigraphy is that a single measurement of GBEF is limited in its representativeness. The timing of the measurement could be a substantial bias. The administration of antibiotics or biliary drainage could result in a change of the contractile function measurements.

Interesting data relevant to contractility of the gallbladder was a higher trend of GBEF in patients with steatocholecystitis, although statistically insignificant after adjusting for confounding factors (Tables 3-6). This finding is opposite from the noted concept and there has been no evidence for the association between higher gallbladder contractility and steatocholecystitis. According to our study, higher GBEF was associated with steatocholecystitis, irrespective of presence of gallbladder stone in the univariable analysis (Tables 3 and 5). However, there was no significant association in the multivariate analysis. It is inferred that zero \% of GBEF stated above could lead to this inverse relationship and this impact was diminished after adjusting confounding factors (Tables 4 and 6).

In contrast to the previous study performed in Greece, patients with acute cholecystitis were relatively younger in this study [19]. Moreover, patients with steatocholecystitis were younger than patients without steatocholecystitis. The 
mechanism or reason is unclear and further large scale studies are needed to elucidate this issue.

This study has several limitations. It is a retrospective study from a single hospital and a small number of patients were enrolled for the statistical analysis. Another limitation was the lacking information about the type and number of gallbladder stone, antibiotic treatment, and the time of measurement of GBEF. However, contrary to the previous studies, contractile function of the gallbladder was quantified and compared directly between patients with steatocholecystitis and with no steatocholecystitis in our study.

\section{Conclusion}

In conclusion, ejection fraction of gallbladder measured by cholescintigraphy cannot be used for the detection or confirmation of patients with steatocholecystitis. Future studies for the development of biomarkers or surrogate markers reflecting contractile function of gallbladder or indicating fatty gallbladder disease are needed for the diagnosis of steatocholecystitis.

\section{Ethical Approval}

This study was conducted in accordance with the Declaration of Helsinki and approved by an institutional review board of Chuncheon Sacred Heart hospital before initiating the study (2013-85). Patient records or information was anonymized and deidentified prior to analysis.

\section{Conflict of Interests}

The authors disclose that there is no conflict of interests regarding the publication of this paper. No benefits in any form have been received or will be received from a commercial party related directly or indirectly to the subject of this paper.

\section{Authors' Contribution}

Concept is done by Chang Seok Bang, Jai Hoon Yoon; Design is done by Chang Seok Bang, Jai Hoon Yoon; supervision is done by Jai Hoon Yoon; resource is done by Chang Seok Bang, Yong Sub Lee, Youn Jeong Kim, Jin Bong Kim, and Dong Joon Kim; materials are checked by Chang Seok Bang, Yong Sub Lee, Youn Jeong Kim, Jin Bong Kim, and Dong Joon Kim; data collection and/or processing is done by Chang Seok Bang, Yong Sub Lee, Youn Jeong Kim, Jin Bong Kim, and Dong Joon Kim; analysis and/or interpretation is done by Chang Seok Bang, Yong Sub Lee, and Jai Hoon Yoon; literature search is done by Chang Seok Bang, Yong Sub Lee; writing is done by Chang Seok Bang, Yong Sub Lee; critical reviews are checked by Jai Hoon Yoon. Chang Seok Bang and Yong Sub Lee equally contributed to this work.

\section{References}

[1] L. S. Szczepaniak, R. G. Victor, L. Orci, and R. H. Unger, "Forgotten but not gone: the rediscovery of fatty heart, the most common unrecognized disease in America," Circulation Research, vol. 101, no. 8, pp. 759-767, 2007.

[2] H. A. Pitt, "Hepato-pancreato-biliary fat: the good, the bad and the ugly," $H P B$, vol. 9, no. 2, pp. 92-97, 2007.

[3] C.-J. Tsai, M. F. Leitzmann, W. C. Willett, and E. L. Giovannucci, "Central adiposity, regional fat distribution, and the risk of cholecystectomy in women," Gut, vol. 55, no. 5, pp. 708-714, 2006.

[4] C.-J. Tsai, M. F. Leitzmann, W. C. Willett, and E. L. Giovannucci, "Prospective study of abdominal adiposity and gallstone disease in US men," The American Journal of Clinical Nutrition, vol. 80, no. 1, pp. 38-44, 2004.

[5] E. A. Shaffer, "Epidemiology and risk factors for gallstone disease: has the paradigm changed in the 21st century?" Current Gastroenterology Reports, vol. 7, no. 2, pp. 132-140, 2005.

[6] F. Nervi, J. F. Miquel, M. Alvarez et al., "Gallbladder disease is associated with insulin resistance in a high risk Hispanic population," Journal of Hepatology, vol. 45, no. 2, pp. 299-305, 2006.

[7] C.-J. Tsai, "Steatocholecystitis and fatty gallbladder disease," Digestive Diseases and Sciences, vol. 54, no. 9, pp. 1857-1863, 2009.

[8] K. N. Lee and H. S. Choi, "Steatocholecystitis," The Korean Journal of Gastroenterology, vol. 55, no. 6, pp. 347-349, 2010.

[9] H. W. Hendel, L. Højgaard, T. Andersen et al., "Fasting gall bladder volume and lithogenicity in relation to glucose tolerance, total and intra-abdominal fat masses in obese non-diabetic subjects," International Journal of Obesity, vol. 22, no. 4, pp. 294302, 1998.

[10] M. L. Petroni, “Gall-bladder motor function in obesity," Alimentary Pharmacology and Therapeutics, vol. 14, no. 2, pp. 48-50, 2000.

[11] E. M. H. Mathus-Vliegen, M. L. van Ierland-van Leeuwen, and A. Terpstra, "Determinants of gallbladder kinetics in obesity," Digestive Diseases and Sciences, vol. 49, no. 1, pp. 9-16, 2004.

[12] H. A. J. Gielkens, W. F. Lam, M. Coenraad et al., "Effect of insulin on basal and cholecystokinin-stimulated gallbladder motility in humans," Journal of Hepatology, vol. 28, no. 4, pp. 595-602, 1998.

[13] M. Tulchinsky, B. W. Ciak, D. Delbeke et al., "SNM practice guideline for hepatobiliary scintigraphy 4.0," Journal of Nuclear Medicine Technology, vol. 38, no. 4, pp. 210-218, 2010.

[14] R. P. Jazrawi, P. Pazzi, M. L. Petroni et al., "Postprandial gallbladder motor function: refilling and turnover of bile in health and in cholelithiasis," Gastroenterology, vol. 109, no. 2, pp. 582-591, 1995.

[15] Q. Chen, J. Amaral, P. Biancani, and J. Behar, "Excess membrane cholesterol alters human gallbladder muscle contractility and membrane fluidity," Gastroenterology, vol. 116, no. 3, pp. 678$685,1999$.

[16] L. J. Jennings, Q.-W. Xu, T. A. Firth, M. T. Nelson, and G. M. Mawe, "Cholesterol inhibits spontaneous action potentials and calcium currents in guinea pig gallbladder smooth muscle," The American Journal of Physiology, vol. 277, no. 5, pp. G1017-G1026, 1999.

[17] Q.-W. Xu and E. A. Shaffer, "The potential site of impaired gallbladder contractility in an animal model of cholesterol gallstone disease," Gastroenterology, vol. 110, no. 1, pp. 251-257, 1996.

[18] J. J. S. Kiewiet, M. M. N. Leeuwenburgh, S. Bipat, P. M. M. Bossuyt, J. Stoker, and M. A. Boermeester, "A systematic review and meta-analysis of diagnostic performance of imaging in acute cholecystitis," Radiology, vol. 264, no. 3, pp. 708-720, 2012. 
[19] A. A. Papadopoulos, M. Kateri, K. Triantafyllou et al., "Hospitalization rates for cholelithiasis and acute cholecystitis doubled for the aged population in Greece over the past 30 years," Scandinavian Journal of Gastroenterology, vol. 41, no. 11, pp. 1330-1335, 2006. 


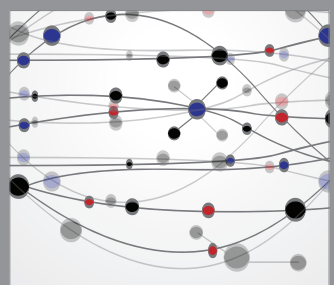

The Scientific World Journal
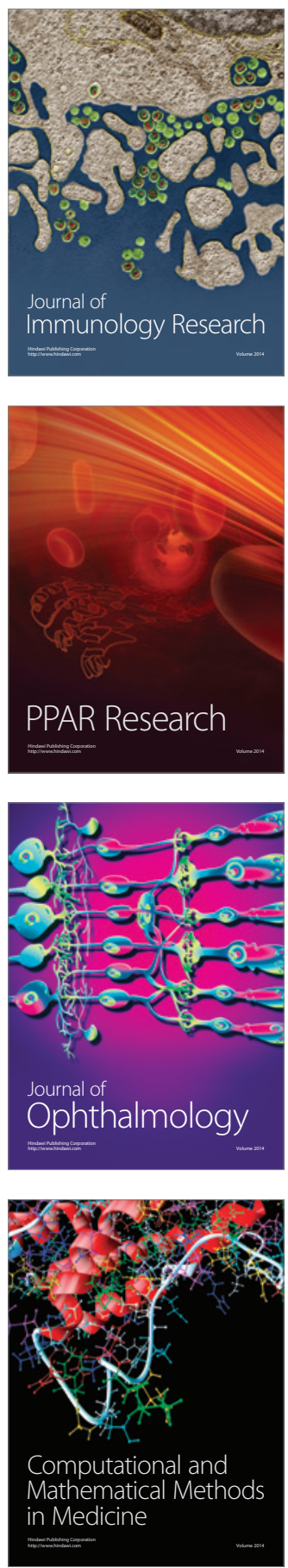

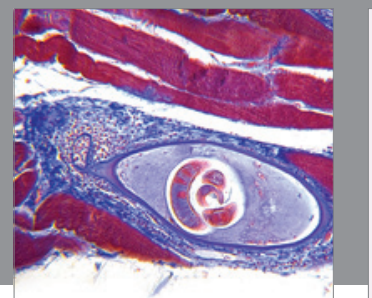

Gastroenterology

Research and Practice
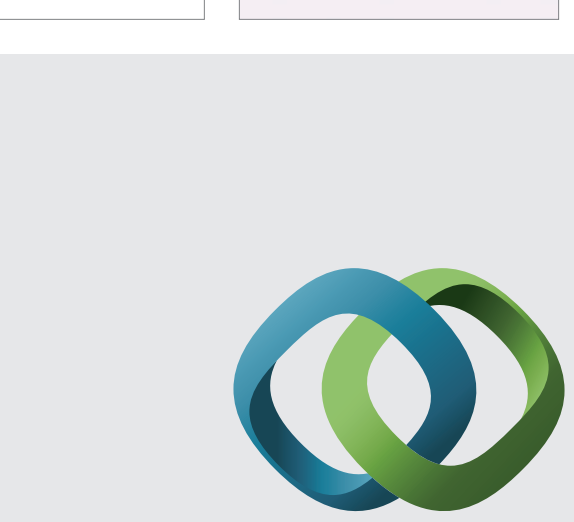

\section{Hindawi}

Submit your manuscripts at

http://www.hindawi.com
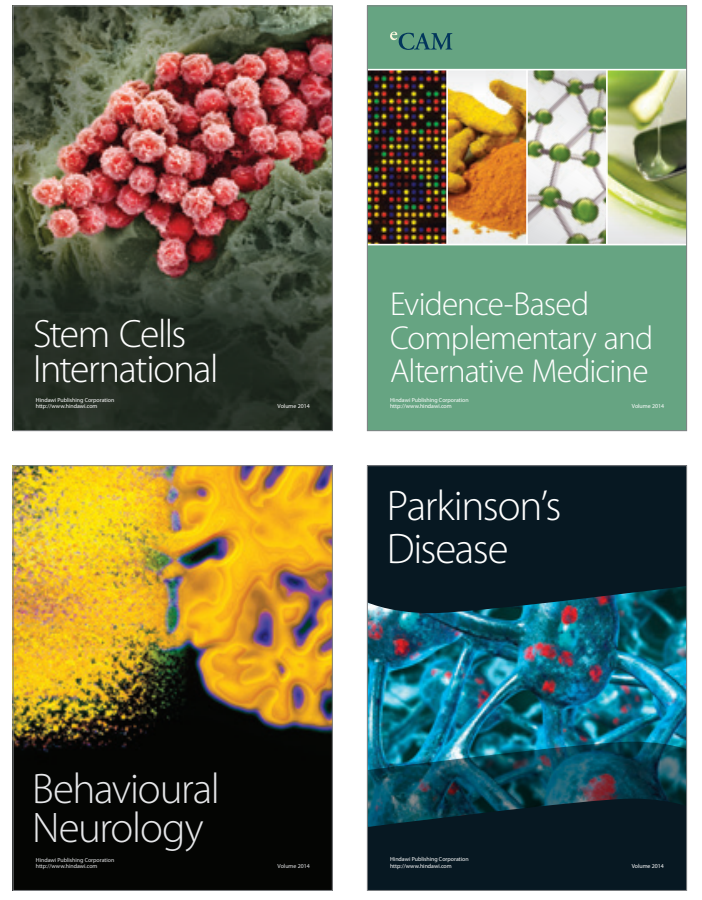
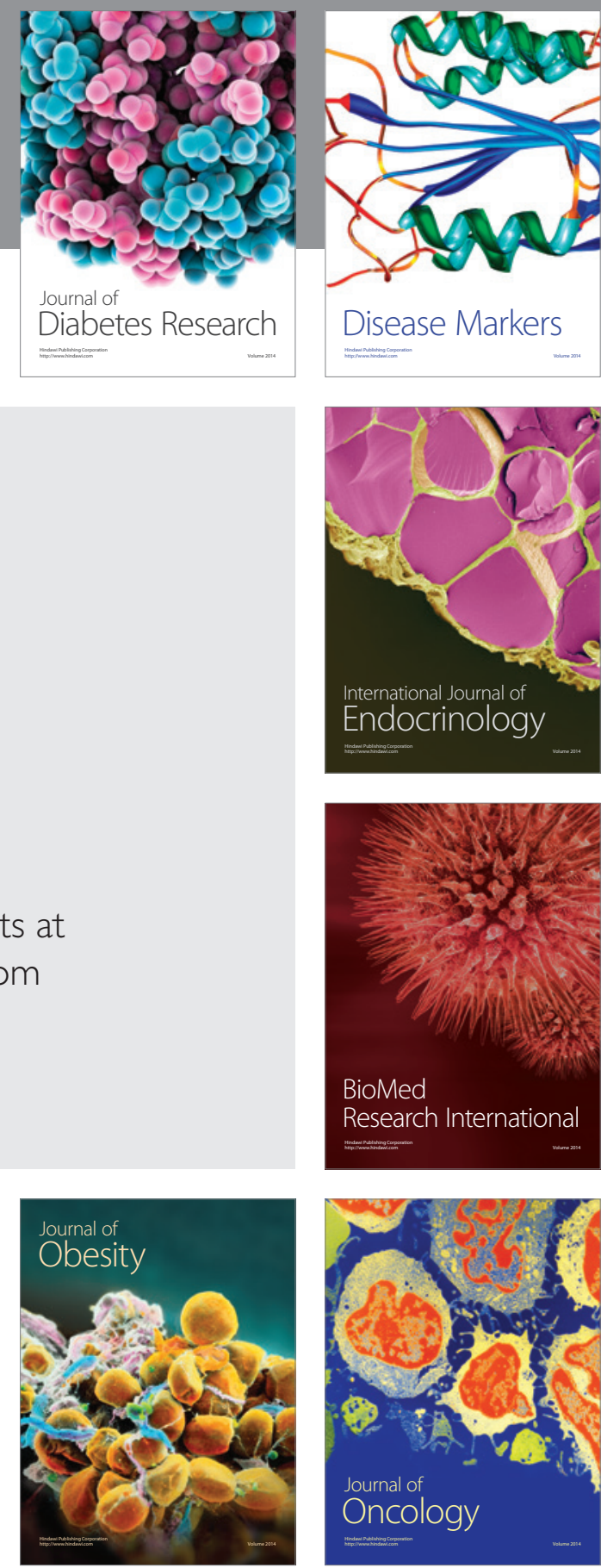

Disease Markers
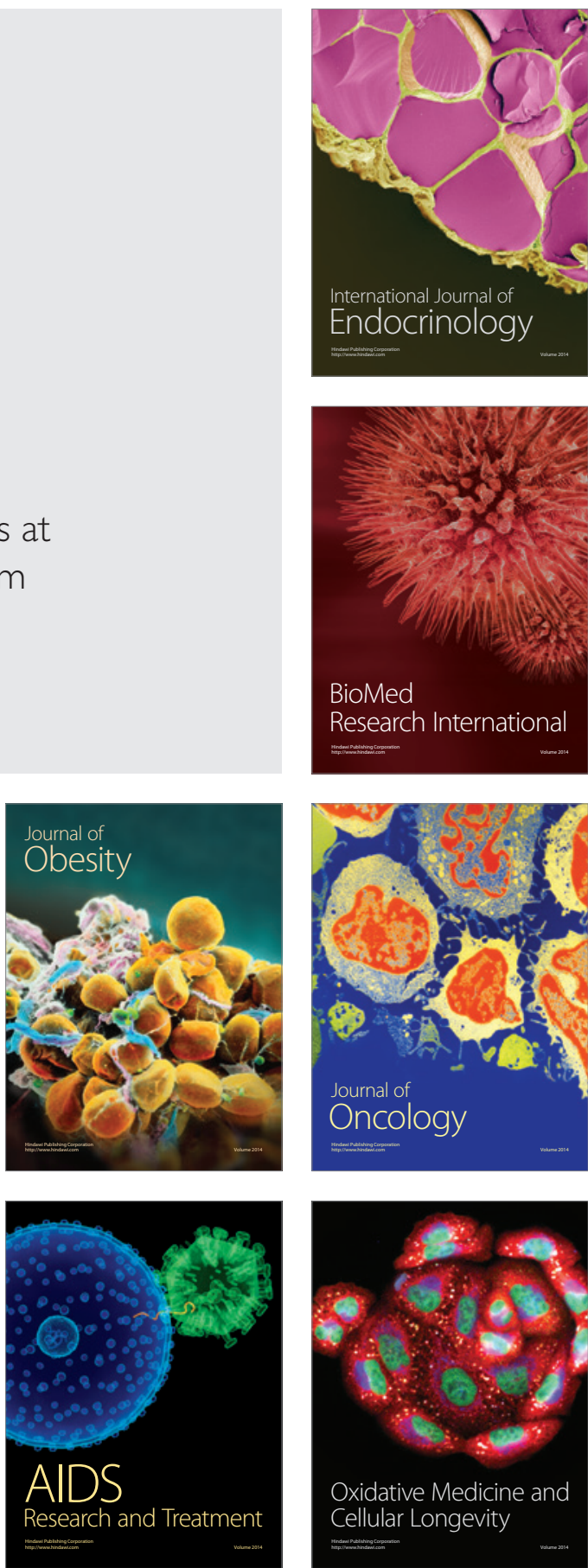